\title{
Study on Continuous Production of Biodiesel Using Fixed Bed Reactors Filled With Anion-Exchange Resins
}

\author{
Takuya Ito ${ }^{1}$, Yusuke Kakuta ${ }^{2}$, Katsumi Hirano ${ }^{2} \&$ Toshinori Kojima ${ }^{1}$ \\ ${ }^{1}$ Department of Materials and Life Science, Seikei University, Japan \\ ${ }^{2}$ Department of Materials and Applied Chemistry, Nihon University, Japan \\ Correspondence: Takuya Ito, Department of Materials and Life Science, Seikei University, 3-3-1 \\ Kichijoji-kitamachi, Musashino-shi, Tokyo, Japan. Tel: 81-42-237-3733. E-mail: takuya.ito@st.seikei.ac.jp
}

Received: October 31, 2013 Accepted: February 15, 2014 Online Published: April 29, 2014

doi:10.5539/eer.v4n2p47 URL: http://dx.doi.org/10.5539/eer.v4n2p47

\begin{abstract}
The biodiesel attracts attention as a fossil alternative fuel. It has turned out to be effective to use the methoxide type anion-exchange resin as a catalyst for the biodiesel production. However, the problem of the resin deactivation in the fixed bed reactor still remains. The deactivation mechanism of the resin in the reactor for the biodiesel production was investigated. As a result, it was clarified that the contact of the resin with triglycerides of the reactant was obstructed by glycerin of the byproduct absorbed by the resin. It was suggested that increasing the linear velocity in the reactor decreased the adsorption of glycerins, so that the deactivation of the resin could be controlled. Moreover, the setting up drift plates in the reactor could improve the yield of biodiesel.
\end{abstract}

Keywords: biodiesel, anion-exchange resin, transesterification, fixed bed reactor, catalyst lifetime

\section{Introduction}

According to the Petroleum Association of Japan Petroleum Industry (2013), about 33\% of the world primary energy demand is met by petroleum, and the world petroleum demand in 2012 was 89.7 million barrels/day. According to the estimates by the International Energy Agency, demand will reach 95.7 million barrels/day by 2017, an increase of 7\% of 2012 levels or 5 million barrels/day, with the increase in demand centering on China and Asia. However, the reserves-to-production ratio is about 59 years, and there is a concern of depletion (Petroleum Association of Japan Petroleum Industry, 2013).

Since most of the petroleum is consumed in internal combustion engines, development of a light liquid fuel as an alternative to petroleum for use in existing internal-combustion engines is urgent. Biodiesel is attracting attention as one of the possible alternative fuel to petroleum. Basically, biodiesel is comprised of fatty acid methyl esters (FAMEs), which are produced by the transesterification of triacylglycerols, the main component of fats and oils, with methanol and homogeneous alkali catalysts (Ex. $\mathrm{NaOH}, \mathrm{KOH}$, ect.). Biodiesel can be used in existing diesel engines, and as it vanishingly contain sulfur, $\mathrm{SO}_{\mathrm{X}}$ is hardly emitted. In addition, the flash point of biodiesel is high and complete combustion can be achieved, with reduced emissions of $\mathrm{HC}, \mathrm{CO}$, and black smoke.

In Europe, production of biodiesel from virgin vegetable oils exceeds 3 million tons per year in 2007, and production is increasing (Matsumura, 2007). In Japan, it is difficult to secure enough land to cultivate sufficient quantities of raw plant material. Therefore, biodiesel production from post-consumer fat and oil, such as waste cooking oil, is sought-after. However, the used cooking oil contains free fatty acids (FFAs). FFAs react with the alkali catalyst and produce soap. Soap takes BDF into the water in the washing process and decreases the product yield (Horie, Sugano, Hirano, \& Mashimo, 2006). Moreover, the use of the homogeneous alkali catalysts causes the procution of the harmful alkaline waste fluids in the water washing process (Saka, 2007). Then, the authors paid attention to the two step ion exchange resin method. This method involves two steps: esterification of FFAs using cation exchange resin in the 1st step and transesterification of triacylglycerols using anion exchange resin in the 2nd step. As a result, the continuous process with a fixed-bed reactors can be constructed without the soap generation or the water washing process. The high durability of the cation exchange resin has already been reported (Kouzu, Nakagaito, \& Hodaka, 2011). However, the durability of the anion exchange resin was poor, because the hydroxyl ions of the anion exchange resins caused the hydrolysis of triacylglycerol and the fatty acids were generated (SHIBASAKI \& KITAKAWA, 2007). The authors reported that when the hydroxyl 
ion of the anion exchange resin is exchanged with the methoxide ion, the fatty acid is not generated (Hirano, Ito, Kakuta, Sugano, \& Mashimo, 2010). Hence, the applicability to the fixed bed reactor of the methoxide $\left(\mathrm{CH}_{3} \mathrm{O}\right)$ type resin is examined in this paper.

\section{Methods}

\subsection{Catalyst Preparation}

Anion exchange resin (Organo Corporation, IRA204Cl) of $400 \mathrm{~mL}$ was swelled in methanol and was filled the column with glass filter. The sodium methylate-methanol solution $(1 \mathrm{~mol} / \mathrm{L})$ of $4 \mathrm{~L}$ was poured into the column at the speed of $\mathrm{SV}=4 \mathrm{~h}^{-1}$. Next, methanol of $8 \mathrm{~L}$ was poured into it at the speed of $\mathrm{SV}=10 \mathrm{~h}^{-1}$. Methanol of 500 $\mathrm{ml}$ was poured into it under pressure. The obtained resin was regarded to be fully converted into the $\mathrm{CH}_{3} \mathrm{O}$ type.

Table 1 lists physical properties of the anion exchange resin used.

Table 1. Properties of anion exchange resin

\begin{tabular}{lc}
\hline Amberlite IRA904Cl & \\
\hline Character & Anion \\
Group & $-\mathrm{N} \equiv\left(\mathrm{CH}_{3}\right)_{3} \mathrm{X}$ \\
Type & Macro reticular \\
Ion-exchange capacity $[\mathrm{mol} / \mathrm{kg}$-resin] & $\geq 4.2$ \\
Specific surface area $\left[\mathrm{m}^{2} / \mathrm{g}-\mathrm{resin}\right]$ & 46.9 \\
Particle size $[\mathrm{mm}]$ & $0.40-0.56$ \\
\hline
\end{tabular}

\subsection{Transesterification}

The process flow of the fixed bed reactor used is shown in Figure 1.

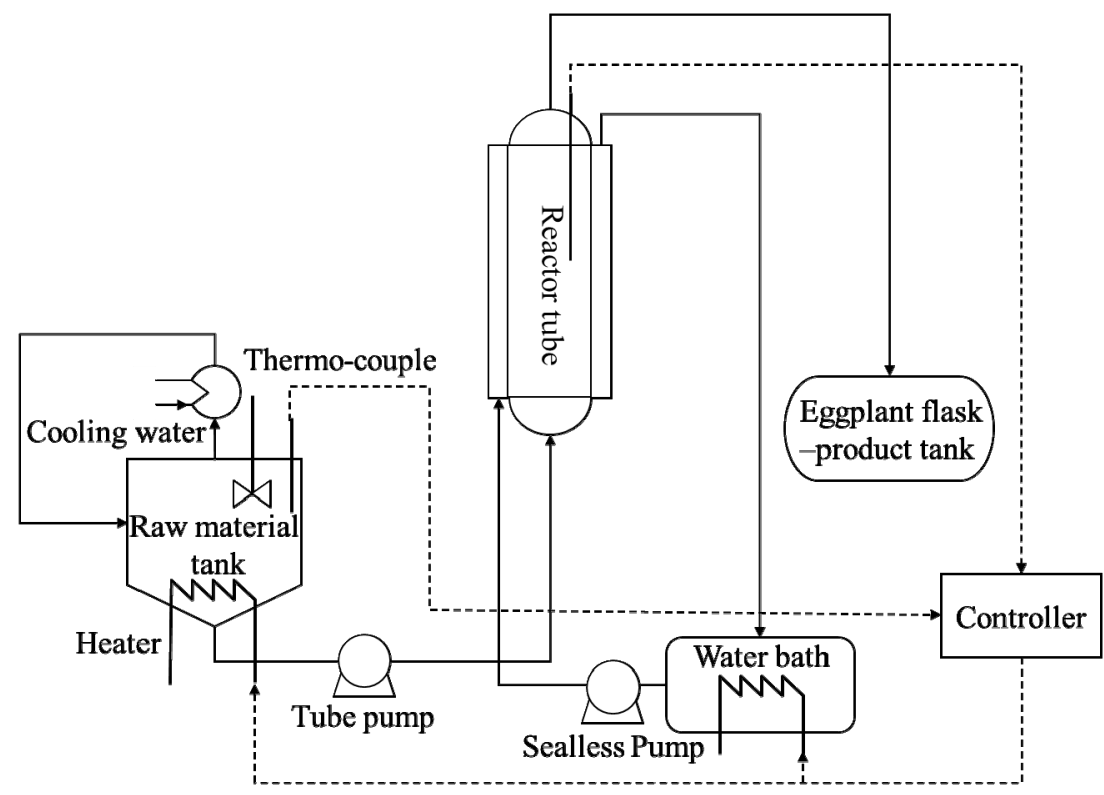

Figure 1. Process flow

The reaction tube (Length/diameter ratio $(\mathrm{L} / \mathrm{D})=5,15$ or 45 keeping capacity constant at $400 \mathrm{ml}$ ) was filled with the $\mathrm{CH}_{3} \mathrm{O}$ type resin. A thermocouple, a nitrogen supply nozzle, and a Dimroth condenser were installed in the feedstock tank ( $2 \mathrm{~L}$ capacity). The soybean oil, the methanol ( $90 \mathrm{wt} \%$ - soybean oil basis), and the methyl oleate ( $200 \mathrm{wt} \%$ - soybean oil basis) were put in the feedstock tank. The methyl oleate was used because it was one of the main component of FAME and in the actual operation, FAME was used as a mixuture. The soybean oil and the methanol were used as feedstocks, and the methyl oleate as a homogenizing solvent. There is a possibility 
that the transesterification doesn' occur when oils and fats and the methanol are not homogeneously mixed in the fixed-bed reactor (Ito, Kakuta, Sugano, \& Hirano, 2011). The feedstock tank was kept warm at $50{ }^{\circ} \mathrm{C}$ with an immersed heater. Liquor in the feedstock tank was stirred by a magnetic stirrer. The liquid in the feedstock tank was sent to from the bottom of the reaction tube with a tube pump at the rate of $0.5 \mathrm{ml} / \mathrm{min}$ and flowed to an eggplant flask from the top and the flask was replaced with a fresh one every hour. The continuous operation was done for $60 \mathrm{~h}$. The sample in the flask was analyzed by ${ }^{1} \mathrm{H}-\mathrm{NMR}$. The proton peak area from $\mathrm{H}$ in the methoxy group of FAME in the NMR is compared with that of $\mathrm{H}$ in the glycerin part of TG, and from the results, FAME yeld is calculated. (Pedro, Miguel, Lilian, \& Maria, 2004).

The reaction tube was equipped with the outer tube in which the warm water in the water bath was circulated with a pump to keep the inner tube temperature at $50^{\circ} \mathrm{C}$.

\subsection{Removal of Adsorbate From Resin}

The column with the glass filter was filled with the spent resin after the above $60 \mathrm{~h}$ run. Two separate expriments for 15 and $30 \mathrm{~h}$ were also conducted to analyse the same as follows using the column of $\mathrm{L} / \mathrm{D}=5$. First of all diethyl ether of $500 \mathrm{ml}$ was poured into the column at the speed of $\mathrm{SV}=10 \mathrm{~h}^{-1}$ to physically remove the oil adhering to the resin. Next, citric acid methanol solution of $2.3 \mathrm{~L}$ was poured into the column at the speed of SV $=4 \mathrm{~h}^{-1}$. The adsorbed material was recovered by evaporative removal of the methanol and diethyl ether from the effluent. The resin adsorbates were quantitatively analysed by column chromatography and GC-MS. The condition of column chromatography is shown in Table 2 and the condition of GC-MS is shown in Table 3.

Table 2. Condition of column chromatography

\begin{tabular}{lll}
\hline Column & $5 \mathrm{wt} \%$ water content silica gel $65 \mathrm{~g}$, dia. $24 \times 160 \mathrm{~mm}$ \\
\hline Sample amount & $1 \mathrm{~g}$ & \\
$\begin{array}{l}\text { Dissolution medium } \\
\text { Diethyl ether / n-Hexane (1:99, vol.) }\end{array}$ & $200 \mathrm{ml}$ & \\
Diethyl ether / n-Hexane (13:87, vol.) & $200 \mathrm{ml}$ & (FAME) \\
Diethyl ether / n-Hexane (50:50, vol.) & $150 \mathrm{ml}$ & (Triacyl glyceride) \\
Diethyl ether & $100 \mathrm{ml}$ & (Diacyl glyceride) \\
& & (Monoacyl glyceride) \\
\hline
\end{tabular}

Table 3. Condition of GC-MS

\begin{tabular}{lcc}
\hline Injector temperature $\left[{ }^{\circ} \mathrm{C}\right]$ & 380 & \\
Ion source temperature $\left[{ }^{\circ} \mathrm{C}\right]$ & 200 & \\
Interface temperature $\left[{ }^{\circ} \mathrm{C}\right]$ & 345 & \\
Pressure $[\mathrm{kPa}]$ & 124.4 & \\
Total flow rate $[\mathrm{ml} / \mathrm{min}]$ & 111.5 & \\
Column flow rate $[\mathrm{ml} / \mathrm{min}]$ & 2.13 & \\
Linear velocity $[\mathrm{cm} / \mathrm{s}]$ & 52.9 & 1 \\
\hline Rate $\left[{ }^{\circ} \mathrm{C} / \mathrm{min}\right]$ & Column temperature $\left[{ }^{\circ} \mathrm{C}\right]$ & Retention time $[\mathrm{min}]$ \\
\hline- & 50 & 0 \\
15 & 180 & 0 \\
7 & 230 & 10 \\
\hline 30 & 380 & \\
\hline
\end{tabular}

\section{Result and Discussion}

\subsection{Durability in Fixed Bed Reactor of $\mathrm{CH}_{3} \mathrm{O}$ Type Resin}

The FAME yield by the transesterification in the fixed bed reactor filled with the $\mathrm{CH}_{3} \mathrm{O}$ type resin is shown in Figure 2. The recovered amounts of adsorbates from the spent resin are shown in Figure 3. The time variation of the amount of the glycerin absorbed to the resin is shown in Figure 4, comparing the amount of active sites of the resin (Hirano et al., 2010) in the column and the produced amount of glycerin calculated from integrated amount 
of produced FAME in Figure 2 assuming one mole of glycerin is produced for three moles of FAME production.

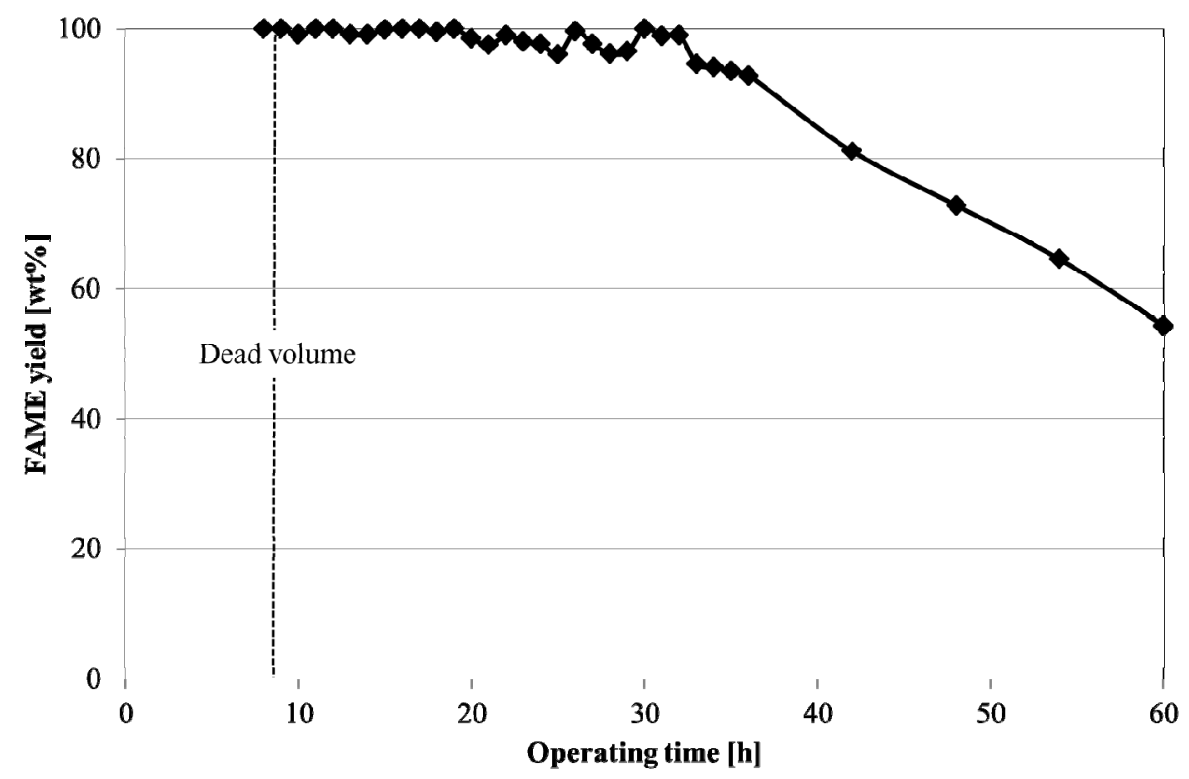

Figure 2. FAME yield of transesterification in fixed bed reactor $(\mathrm{MeOH} 90 \mathrm{wt} \%$, Methyl oleate $200 \mathrm{wt} \%$, $\mathrm{L} / \mathrm{D}=5$ )

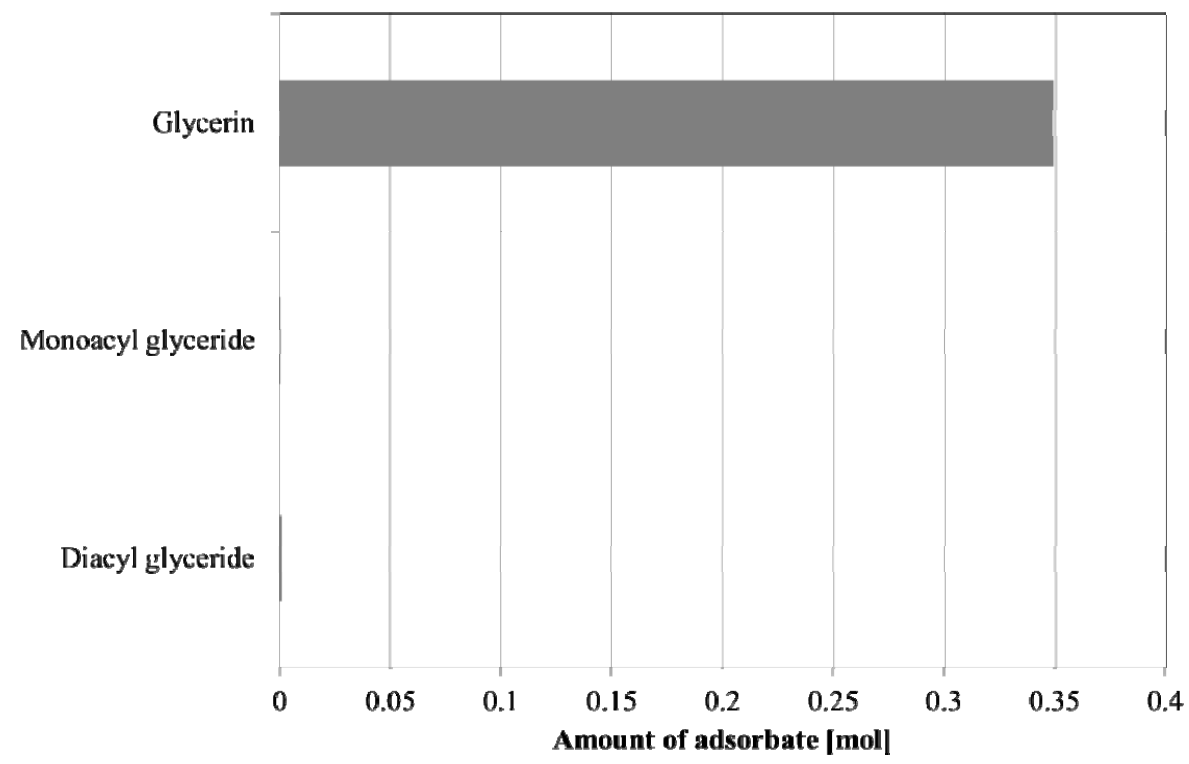

Figure 3. Amount of adsorbate of spent resin (MeOH $90 \mathrm{wt} \%$, Methyl oleate $200 \mathrm{wt} \%, \mathrm{~L} / \mathrm{D}=5$ ) 


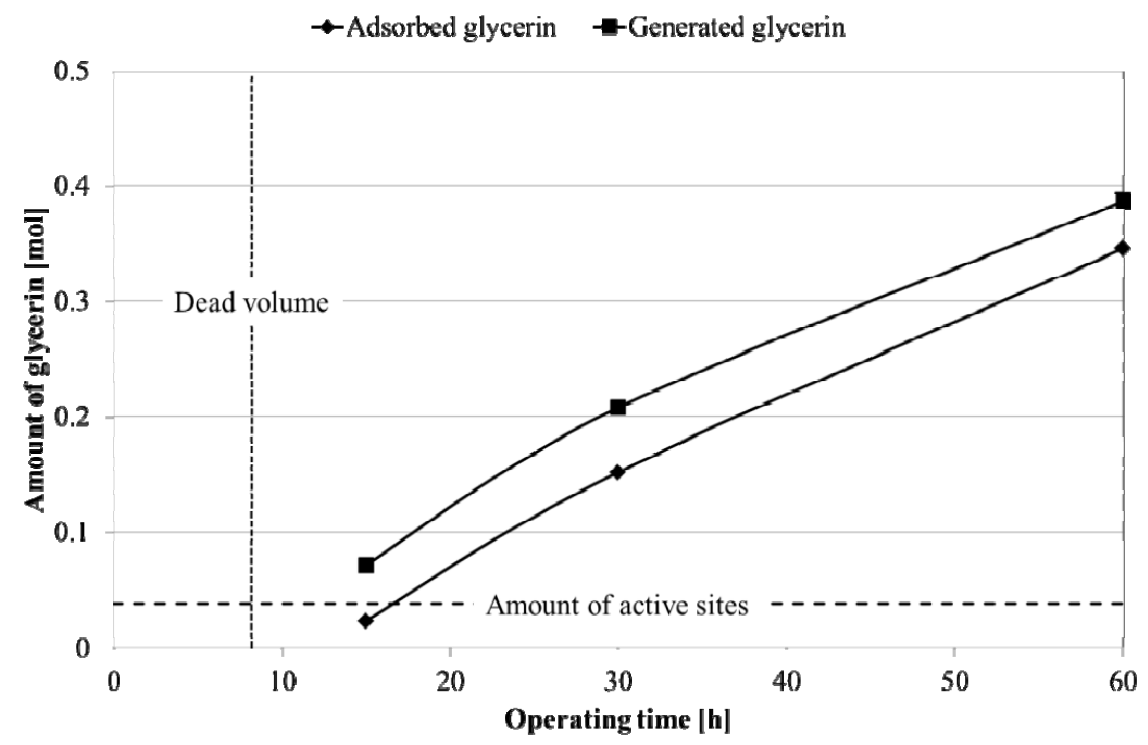

Figure 4. The variation with time of the amount of absorbed glycerin $(\mathrm{MeOH} 90 \mathrm{wt} \%$, Methyl oleate $200 \mathrm{wt} \%$,

$$
\mathrm{L} / \mathrm{D}=5)
$$

As shown in Figure 2, the FAME yield started to decrease around $30 \mathrm{~h}$ after. As shown in Figures 3 and 4, the main component of absorbed materials was found to be glycerin and most of the generated glycerin was adsorbed by the resin. Moreover, the amount of the adsorbed glycerin was much larger than the amount of active sites of the resin.

It was found that the deactivation occurred even when the $\mathrm{CH}_{3} \mathrm{O}$ type resin that didn't generate fatty acid was used in the fixed bed reactor. It is thought that the cause of the resin deactivation is adsorption of the glycerin of the byproduct by the resin. Generally, chemisorption is known as the cause of the deactivation when the ion exchange resin is used (Oberhauser, Lavacchi, Vizza, Capozzoli, \& Lee, 2013; Pyrlik et al., 2012). However, because the amount of adsorbed glycerin were much more than that of active sites of resins, it is thought that this phenomena is caused not by chemisorption on the active site of the resin but broad-sense physisorption in the pores of it.

\subsection{Removal of Adsorbed Glycerin}

Effect of L/D on amount of the glycerin adsorbed by resin is shown in Table 4. Effect of L/D on the FAME yield is shown in Figure 5.

Table 4. Effect of L/D on amount of the glycerin adsorbed by resin (MeOH $90 \mathrm{wt} \%$, Methyl oleate $200 \mathrm{wt} \%$, $\mathrm{L} / \mathrm{D}=5)$

\begin{tabular}{lccc}
\hline Length/diameter radio (L/D) & 5 & 15 & 45 \\
\hline Amount of the glycerin [mol] & 0.35 & 0.22 & 0.12 \\
\hline
\end{tabular}

As shown in Table 4, the amount of the glycerin adsorbed by the resin decreases as L/D increases keeping total volume unchanged. The present results may be explained by the increased physical shear stress to the resin with increased linear velocity. As a result, it is thought that removing the glycerin adsorbed by the resin is promoted. As shown in Figure 5, the decreased tendency to the FAME yield was inhibited by increasing the L/D. It is thought that removing the glycerin adsorbed by the resin is promoted because of an increase in the linear velocity according to an increase in $\mathrm{L} / \mathrm{D}$ and the deactivation of the resin was inhibited. It was found that in order to inhibit the deactivation of the resin, it was effective to remove the glycerin adsorbed by the resin by increasing the linear velocity.

Discussion for promotion of transesterification and its verification by additional experiments 


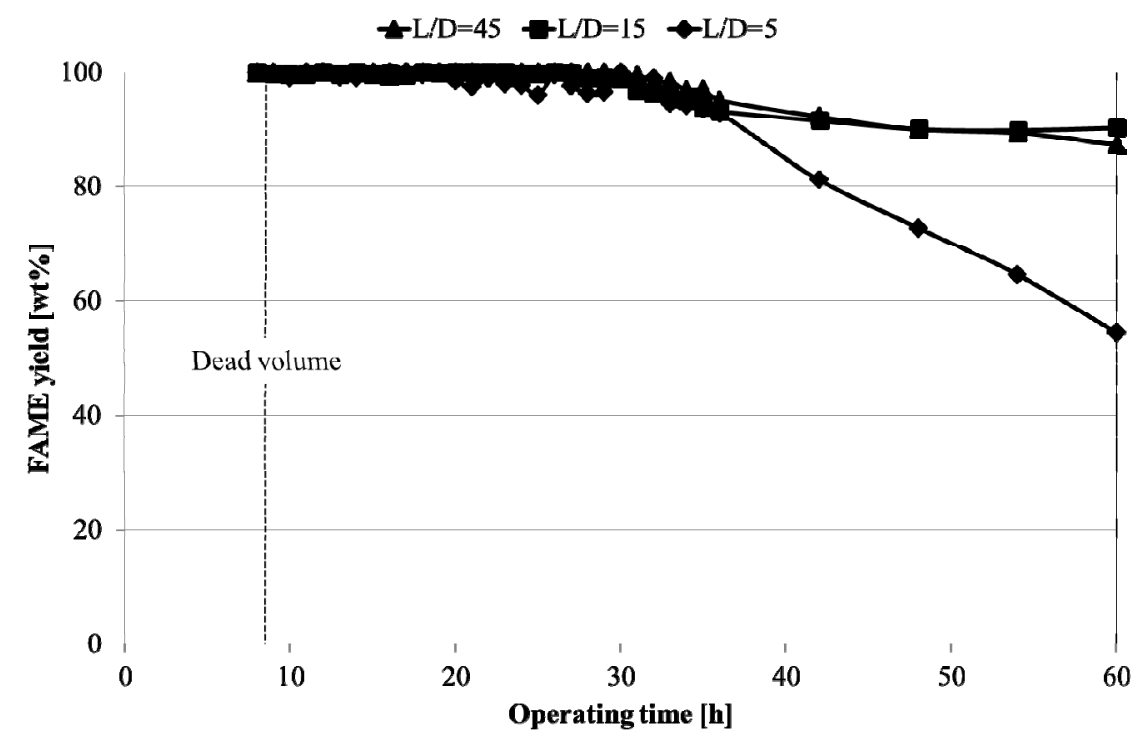

Figure 5. Effect of L/D on the FAME yield (MeOH $90 \mathrm{wt} \%$, Methyl oleate $200 \mathrm{wt} \%$ )

\subsection{Discussion on Factors for Increasing FAME Yield}

Decrease of concentration of the methyl oleate used as homogenizing solvent and increase of that of the methanol are effective for equilibrium shift to the right. The problem of bypass upflow of phase-separated methanol without reaction occurs, when concentration of the methyl oleate is decreased. It was tried that the sufficient residence time of the methanol is secured by inserting the drift plates.

\subsection{Modification of Reactor Configuration for Increasing FAME Yield}

The same reaction tube $(\mathrm{L} / \mathrm{D}=5)$ used in Chapter 2.2 was also used, while 13 drift plates were installed in it at equal intervals as shown in Figure 7. The linear velocity in the modified reactor is equivalent to $L / D=45$ and the removal effects of gryceline by the shear stress is also expected. Furthermore, the revision of the flow direction may be expected to inhibit the bypass upward flow of phase-separated methanol which may increase the retention time of methanol.

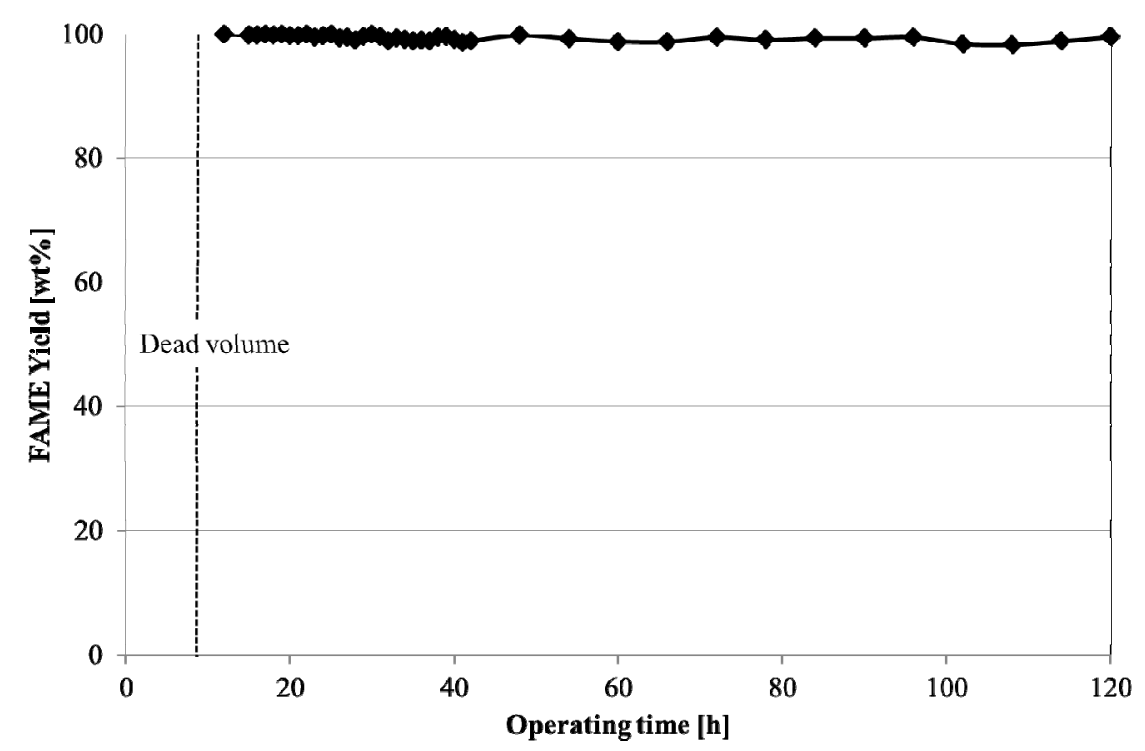

Figure 6. Effect of insertion of drift plates in reaction tube (MeOH $272.5 \mathrm{wt} \%$, Methyl oleate $0 \mathrm{wt} \%, \mathrm{~L} / \mathrm{D}=5)$ 


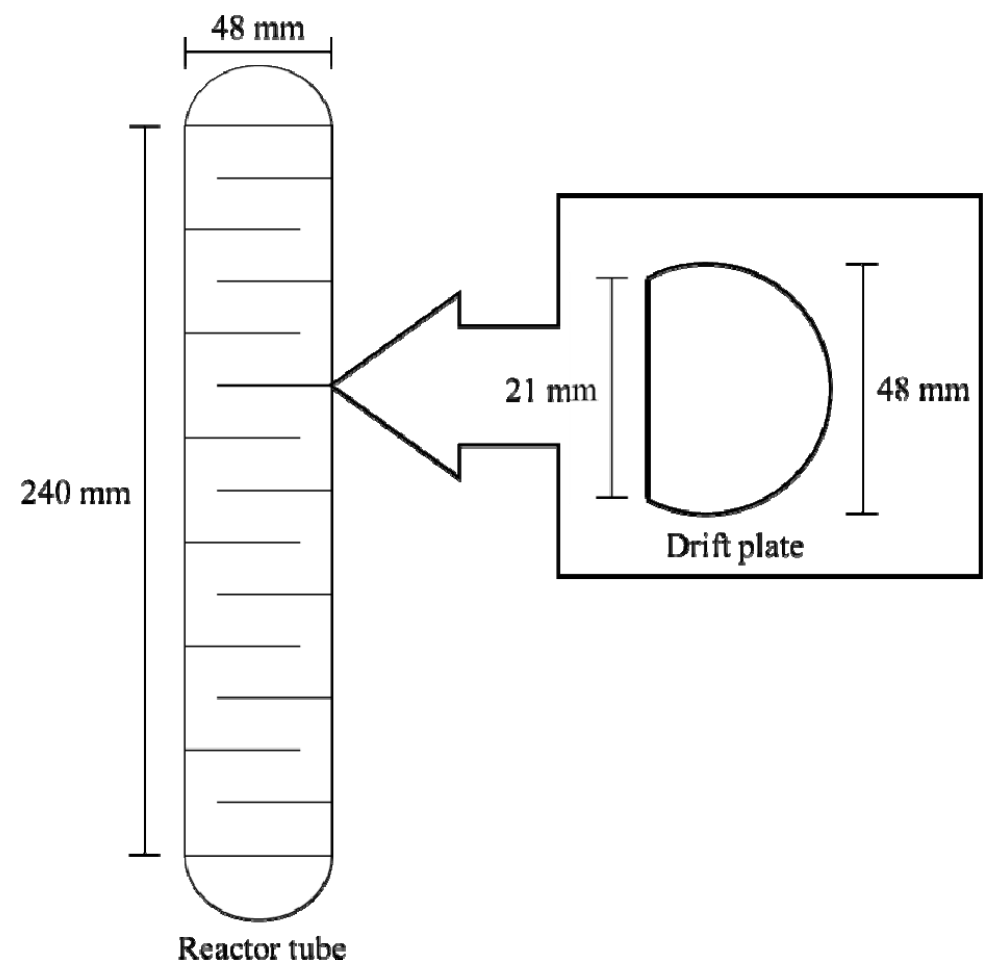

Figure 7. Configuration of drift plates

The soybean oil and the methanol (275.5 wt\% - soybean oil basis) were put in the feedstock tank. The volume concentration of soybean oil in the feedstock tank of this time was equal to the condition in Chapter 2.2. The continuous operation was done for $120 \mathrm{~h}$. The other experimental setups and conditions are same as those in Section 2.2.

\subsection{Demonstration Results}

The FAME yield when the drift plates were inserted in the reaction tube is shown in Figure 6. The FAME yield was maintained for $120 \mathrm{~h}$. Glycerins adsorbing on the resin at this time were measured to be 0.023 mol. It was found to be possible that the FAME yield is maintained high enough by the methanol concentration increase, the methyl oleate concentration decreases, while inserting the drift plates in the reaction tube.

\section{Conclusion}

It was clarified that the contact of the resin with triglycerides of the reactant was obstructed by glycerins of the byproduct adsorbed by the resin even when the $\mathrm{CH}_{3} \mathrm{O}$ type resin that doen't generate fatty acid was used in the fixed bed reactor. It was suggested that increasing the linear velocity in the reactor tube decreased the adsorption of glycerin, so that the deactivation of the resin could be inhibited. The durability of the $\mathrm{CH}_{3} \mathrm{O}$ type resin has been improved by the methanol concentration increase, the FAME concentration decrease, and inserting the drift plates in the reaction tube.

\section{Reference}

Hirano, K., Ito, T., Kakuta, Y., \& Sugano, M. (2010). Biodiesel Fuel Production from Waste Animal Fats Using Alternative Solid Catalysts. Journal of the Japan Institute of Energy, 89(1), 36-41. http://dx.doi.org/10.3775/jie.89.36

Horie, R., Sugano, M., Hirano, K., \& Mashimo, K. (2006). Proceedings of the 15th Annual Conference of the Japan. Institute of Energy, 15, 211-212.

Ito, T., Kakuta, Y., Sugano, M., \& Hirano, K. (2011). Proceedings of the 15th Annual Conference of the Japan. Institute of Energy, 20, 72-73.

Kouzu, M., Nakagaito, A., \& Hidaka, J. S. (2011). Pre-esterification of FFA in plant oil transesterified into biodiesel with the help of solid acid catalysis of sulfonated cation-exchange resin. Applied Catalysis A: General, 405(1), 36-44. http://dx.doi.org/10.1016/j.apcata.2011.07.026 
Matsumura, M. (2007). Bio liquid fuel, 27-239.

Neto, P. R. C., Caro, M. S. B., Mazzuco, L. M., \& da Graça Nascimento, M. (2004). Quantification of soybean oil ethanolysis with 1H NMR. Journal of the American Oil Chemists' Society, 81(12), 1111-1114. http://dx.doi.org/10.1007/s11746-004-1026-0

Oberhauser, W., Lavacchi, A., Vizza, F., Capozzoli, L., \& Lee, H. M. (2013). Aerobic diol lactonization by Au-nanoparticles supported onto an anion-exchange resin. Applied Catalysis A: General, 451, 58-64. http://dx.doi.org/10.1016/j.apcata.2012.11.012

Petroleum. (2013). Association of Japan Petroleum Industry in Japan, 3-8

Pyrlik, A., Hoelderich, W. F., Müller, K., Arlt, W., Strautmann, J., \& Kruse, D. (2012). Dimethyl carbonate via transesterification of propylene carbonate with methanol over ion exchange resins. Applied Catalysis B: Environmental, 125, 486-491. http://dx.doi.org/10.1016/j.apcatb.2011.09.033

Saka, S. (2007). Recent Progress in biofuels for its production and Utilization. Journal of Environmental Conservation Engineering, 36(12), 842-846.

Shibasaki-Kitakawa, N., Honda, H., Kuribayashi, H., Toda, T., Fukumura, T., \& Yonemoto, T. (2007). Biodiesel production using anionic ion-exchange resin as heterogeneous catalyst. Bioresource Technology, 98(2), 416-421. http://dx.doi.org/10.1016/j.biortech.2005.12.010

\section{Copyrights}

Copyright for this article is retained by the author(s), with first publication rights granted to the journal.

This is an open-access article distributed under the terms and conditions of the Creative Commons Attribution license (http://creativecommons.org/licenses/by/3.0/). 